\title{
De la letra de la constitución a la realidad de las prácticas: formas de construcción del estado y la ciudadanía en tres estados rioplatenses durante la primera mitad del siglo XIX
}

\author{
Pablo Buchbinder \\ Universidad Nacional de General Sarmiento \\ y Universidad de Buenos Aires, Argentina
}

El artículo examina la ambigua relación entre textos constitucionales y prácticas políticas en tres estados sudamericanos durante la primera mitad del siglo XIX. El estudio se centra especialmente en cuestiones tales como la construcción de la ciudadanía, el poder miliciano, los cambios en la organización municipal y la cuestión del sufragio en Corrientes, Paraguay y Uruguay.

PALABRAS ClAVE: constitución, estado, ciudadanía, federalismo.

This article examines the ambivalent relation between Constitutional Texts and Political Practices in three South American States during the XIX Century. The Study focuses on the Building of Citizenship, the changes of the system of local government, the military power and the Electoral System in Corrientes, Paraguay and Uruguay.

KEYWORDS: constitution, state, citizenship, federalism.

\section{La realidad estatal en la Cuenca del Plata en la primera mitad del siglo XIX}

El propósito de este trabajo consiste en explorar una serie de problemas y cuestiones relativas a los vínculos entre prescripciones constitucionales y prácticas políticas en tres organizaciones estatales de la Cuenca rioplatense durante la primera mitad del siglo XIX. Se trata de la provincia de

1 El autor agradece el apoyo brindado por la Fundación Alexander von Humboldt, el Servicio Exterior de Intercambio Académico Alemán y el Colegio de Michoacán para asistir al coloquio "Los inicios del Constitucionalismo en América y Europa, 1770-1850" en noviembre de 2003, donde presentó una versión preliminar de este texto. El texto definitivo fue elaborado durante una estancia como becario Humboldt en el Instituto Iberoamericano de Berlín durante febrero y marzo de 2007. 
Corrientes que, entre 1820 y 1853, constituye un estado autónomo y las Repúblicas del Paraguay y Uruguay. Como se sabe, tras la disolución del Virreinato del Río de la Plata en 1816 y la caída del gobierno central de las llamadas Provincias Unidas del Río de la Plata en 1820, el panorama estatal y político de la región estuvo dominado por un conjunto de estados autónomos que mantuvieron distinto tipo de vínculos y asociaciones entre sí sin llegar a integrarse en una única estructura institucional. Esos estados dictaron sus propias constituciones, siendo éstas la base sobre la que establecieron la forma de gobierno y la administración de su territorio, organizando de esta manera su funcionamiento interno hasta la segunda mitad del siglo XIX.

En este trabajo examinamos especialmente las Constituciones correntinas de 1821, 1824 y 1855, la Constitución de la República del Uruguay sancionada en 1830 y la ley que estableció la Administración política de la República del Paraguay en 1842. ${ }^{2}$ Nos proponemos analizar aquí cómo, a través de estas Cartas, las distintas fracciones de las elites dirigentes rioplatenses trataron de resolver los problemas que planteaba la conformación de un nuevo orden político en la era postindependentista y los obstáculos que debieron afrontar en este intento. Como acabamos de señalar, el Virreinato del Río de la Plata, que contenía prácticamente a la totalidad de los actuales territorios del Uruguay, Paraguay y de la provincia argentina de Corrientes, se desintegró a partir de 1810 y los ensayos para conformar un único estado independiente sobre el espacio que había ocupado el Virreinato fracasaron, al igual que el intento de establecer una Constitución que rigiese sobre ese mismo espacio. Las Cartas Magnas de 1819 y 1826, sancionadas por Congresos que reunían representantes de diversas regiones del Río de la Plata, encontraron una fuerte oposición y fueron rechazadas por las provincias, en gran medida por su orientación unitaria. En consecuencia, las únicas que gozaron entonces de vigencia efectiva prácticamente hasta 1853 fueron justamente las Constituciones provinciales. ${ }^{3}$

2 La documentación constitucional fue extraída, básicamente, de la Recopilación de Constituciones de la Provincia de Corrientes, Edición Oficial, Imprenta del Estado, Corrientes, 1921 y de los textos contenidos en Arosemena, Justo: Constituciones Políticas de la América Meridional, Imprenta de A. Lemale Ainé, Havre, 1870, págs. 325-338 y 261-292.

3 Los procesos de desintegración política de los territorios que componían el antiguo espacio rioplatense han sido analizados entre otros por Hensel, Silke, y Potthast, Barbara: "De la provincia gigante de las Indias a las "republiquetas" del espacio interior ¿Desintegración política a causa de los nacionalismos?" en Potthast, Barbara; Kohut, Kart, y Kolhlhepp, Gerd (eds.): El espacio interior de América del Sur. Geografía, historia, política, cultura", Vervuert, Frankfurt Main-Madrid, 1999, págs. 47-67. 
El origen de las provincias ha sido analizado con relativa profundidad en los últimos años en diversos trabajos. Después de la caída de la Monarquía española se suscitó un claro problema de legitimidad política en el espacio rioplatense, como en otras regiones de Hispanoamérica. Como ha señalado José Carlos Chiaramonte, conocidos los sucesos de la Península, se planteó entre los principales protagonistas de la vida política rioplatense un conflicto que puede sintetizarse a partir de la existencia de dos posiciones. Por un lado se encontraban quienes consideraban que las decisiones sobre la organización y conducción del Estado debían ser tomadas por el conjunto de los pueblos soberanos que, de acuerdo a los principios del derecho de gentes, eran personas morales en condición de igualdad. Frente a esta postura se definió otra que insistía en la necesidad de organizar un nuevo Estado encabezado por la antigua capital del virreinato, a la que debían subordinarse el resto de los pueblos. ${ }^{4}$ Progresivamente se fue imponiendo la idea de que existían tantas entidades soberanas como pueblos entendiendo a estos, en principio, como las ciudades y sus Cabildos. Estas ciudades fueron ampliando progresivamente su papel político, redefinieron su jurisdicción y regularon, finalmente, los derechos políticos de los habitantes de la campaña. Así, a partir de la disgregación de las antiguas provincias, del régimen de Intendencias nacieron los nuevos estados provinciales. ${ }^{5}$ Este proceso de definición de las provincias culminó, en casi todos los casos, con la sanción de Cartas constitucionales a través de las cuales las elites que controlaban esos estados buscaron legitimar su poder y organizar su estructura institucional interna. La primera de ellas fue la de Santa Fe en 1819. Luego siguieron las de Entre Ríos en 1822, Catamarca en 1823 y San Juan en 1825. Desde mediados del siglo XIX, sobre la base de diferentes tipos de acuerdos y pactos, catorce de estos estados autónomos o provincias, entre ellos Corrientes, conformaron el Estado nacional argentino, el cual se rigió por una Constitución, sancionada en 1853 y reformada en 1860 , de carácter netamente federal. A partir de entonces, los estados provinciales debieron reformar sus propias normativas para adaptarlas al nuevo orden legal de carácter nacional y federal.

4 Chiaramonte, José Carlos: "El federalismo argentino en la primera mitad del siglo XIX", en Carmagnani, Marcello (ed.): Federalismos latinoamericanos, México, Brasil, Argentina, FCE, México, 1993, págs. 81-127.

5 Véase al respecto Goldman, Noemí: "Crisis Imperial, Revolución y Guerra”, en Goldman, Noemí: Revolución, República, Confederación, Editorial Sudamericana, Buenos Aires, 1998, págs. 21-69. 
Uruguay y Paraguay, cuyos territorios también habían pertenecido al antiguo Virreinato, permanecieron como estados independientes. La Banda Oriental del Uruguay constituyó, como se sabe, un ámbito de disputa entre las fuerzas de los imperios coloniales español y portugués. Su capital, Montevideo, dependía de Buenos Aires y mantenía con ésta viejas disputas vinculadas con el control del comercio y la navegación. Tras la caída de las autoridades coloniales de Buenos Aires en 1810, Montevideo se mantuvo como un baluarte de los españoles. El apoyo a la revolución surgió de la zona rural y estuvo conducido por José Artigas, un antiguo jefe miliciano de fronteras que se convirtió en líder de la campaña. La Banda Oriental ingresó entonces en un estado de guerra permanente, siendo Artigas un defensor entusiasta de la idea federal. Sostenía, además, que toda Constitución debía basarse en la voluntad popular, en la solución republicana, en la división de poderes y en el sistema federal. A partir de 1814, con la retirada de los españoles de Montevideo, Artigas logró el control de toda la Banda Oriental. En 1815 impulsó, a través de un Reglamento Agrario, una profunda transformación de la campaña, propiciando la rápida distribución de la tierra. Este proceso debía llevarse a cabo bajo el principio de que “...los más infelices serán los más privilegiados...”. Señalaba además, expresamente, en lo referido al reparto de las tierras, que "los negros libres, los zambos y los criollos pobres, todos podrán ser agraciados con suertes de estancias....'. El programa artiguista ha sido percibido como expresión de uno de los movimientos más igualitarios surgidos del seno de la revolución rioplatense. Pero este proceso fue interrumpido en 1816 por la invasión portuguesa que se hizo presente, además, en el marco de un severo enfrentamiento de Artigas con el gobierno central de Buenos Aires que, de alguna manera, propició la incursión de los portugueses para así terminar con la influencia del caudillo, que debió exiliarse en el Paraguay a partir de 1820. En julio de 1821, un Congreso Provincial votó la anexión de la Provincia al reino de Portugal, adoptando la denominación de Estado Cisplatino Oriental. Cuatro años más tarde un movimiento revolucionario, encabezado por Juan Antonio Lavalleja y apoyado desde Buenos Aires, se propuso la reintegración del territorio oriental a las Provincias Unidas, lo que provocó una guerra entre éstas y el Brasil que terminó, con la mediación inglesa, en 1828. Como resultado de la Convención Preliminar de Paz de ese año se estableció la independencia del Estado Oriental del Uruguay. También a consecuencia de lo estipulado en la citada Convención se convocó a un Congreso que elaboró la Constitución política del nuevo Estado 
jurada en 1830 y que rigió prácticamente hasta la entrada en vigor de una nueva en $1918 .^{6}$

Los efectos de las guerras y la inestabilidad política y militar que se vivió intensamente en los territorios de la Banda Oriental y parcialmente en el de Corrientes a partir de la revolución se hicieron sentir de manera muy limitada en el del Paraguay. Los intentos de la Junta revolucionaria de Buenos Aires por obtener la adhesión del Paraguay a través del envío de una expedición militar fracasaron. En 1811 un movimiento revolucionario logró conformar una Junta de gobierno con hegemonía criolla y amplias facultades, la cual convocó a un Congreso General que se reunió en septiembre de 1813. Dicho Congreso, compuesto por unos mil diputados electos en "comicios libres" por todos los naturales del país a excepción de los “...procesados por delitos graves que merezcan nota de infamia...", estableció un régimen de gobierno basado en la forma republicana y en un sistema ejecutivo a cargo de dos cónsules. Un nuevo Congreso reunido en octubre de 1814 designó a Gaspar Rodríguez de Francia, un prestigioso letrado egresado de la Universidad de Córdoba, como dictador supremo y otro, en mayo de 1816, lo designó dictador perpetuo.

Durante los gobiernos del doctor Francia y, en menor medida, durante el de su sucesor, Carlos Antonio López, el Paraguay se mantuvo relativamente aislado del resto de las provincias y estados rioplatenses. El objetivo de sus gobernantes radicaba en evitar que los efectos derivados de las guerras de la independencia y de los procesos de movilización social y política que los acompañaron se trasladasen al territorio paraguayo. De todas formas hubo a lo largo de aquellos años un intenso tráfico comercial con el exterior que estaba concentrado básicamente en el puerto de Itapúa, sobre el Paraná. Este tráfico se encontraba, además, estrictamente supervisado por el estado, que obtenía de él los recursos que le permitían sostener su rudimentario sistema burocrático.?

6 Sobre el artiguismo puede verse el clásico trabajo de Sala, Lucía; Rodríguez, Jorge, y De La Torre, Nelson: La revolución agraria artiguista, Ediciones Pueblos Unidos, Montevideo, 1969. Desde otra perspectiva, el de Frega, Ana: "La virtud y el poder. La soberanía particular de los pueblos en el proyecto artiguista", en Goldman, Noemí, y Salvatore, Ricardo (comps.): Caudillismos rioplatenses: Nuevas miradas a un viejo problema, Eudeba, Buenos Aires, 1998, págs. 101-133.

7 Sobre el período hegemonizado por Gaspar Rodríguez de Francia en Paraguay pueden verse, entre otros, los ensayos contenidos en Whigham, Thomas, y Cooney, Jerry W.: El Paraguay bajo el Dr. Francia. Ensayos sobre la sociedad patrimonial, El Lector, Asunción, 1996. Sobre los tiempos de Carlos Antonio y Francisco Solano López pueden consultarse los textos compilados por los mismos autores en El Paraguay bajo los López, Centro Paraguayo de Estudios Sociológicos, Asunción, 1994. 
Gaspar Rodríguez de Francia falleció en 1840 y tras un breve período de inestabilidad fue electo presidente de la República Carlos Antonio López. En 1842 se convocó un Congreso General integrado por trescientos diputados elegidos entre los "...propietarios con capacidad, honrados y de buenos sentimientos...", que sancionó la "Ley que establece la Administración Política de la República del Paraguai”. Esta norma es considerada la primera Constitución del país. En 1856 fue reformada y, en 1870, después de la derrota del Paraguay en la llamada Guerra de la Triple Alianza, se aprobaría una nueva Carta inspirada en la Constitución Argentina sancionada en $1853 .{ }^{8}$ Durante esta misma década el Paraguay reafirmó su condición de estado independiente que había ya establecido tajantemente en la década de 1840. Obtuvo entonces el reconocimiento de ese status por parte del Imperio del Brasil en septiembre de 1844 y por parte de Bolivia, Inglaterra y Francia, poco tiempo después.

La provincia de Corrientes, durante estos mismos años, experimentó un acelerado proceso de cambio vinculado a la progresiva extensión de su frontera y a la incorporación de nuevos territorios. Su capital, fundada en 1588, había ampliado su jurisdicción gradualmente hacia el sur siguiendo el trazo del río Paraná, a lo largo de la etapa colonial, constituyéndose así como un paso en la ruta entre Asunción y Buenos Aires y en los últimos tiempos del período virreinal se conformó en ella una comunidad mercantil vinculada al negocio de los astilleros y al comercio de la yerba mate, el tabaco y la madera. Con el inicio del proceso revolucionario Corrientes se vio gravemente involucrada en las guerras y conflictos entonces desencadenados. La ciudad fue escenario de las luchas en las que tomaron parte las fuerzas criollas, provenientes de Buenos Aires y las del Paraguay, que resistían a las primeras. Las desavenencias entre los propios grupos revolucionarios también se desenvolvieron en el futuro territorio de la provincia. La influencia artiguista, por otro lado, aquí, como en otras provincias rioplatenses, se hizo sentir con fuerza hasta la derrota militar definitiva del caudillo oriental en 1820. Si bien Corrientes se había convertido en provincia por resolución del director supremo de las Provincias Unidas en 1814, las autoridades de la vecina Entre Ríos hicieron sentir su dominio sobre esa provincia. En octubre de 1821, tras la muerte del líder entrerriano Francisco Ramírez, Corrientes recuperó su condición de provincia inde-

8 Veáse al respecto Mariñas Otero, Luis: Las Constituciones del Paraguay, Ediciones Cultura Hispánica, Madrid, 1978. 
pendiente, convirtiéndose, a raíz de la disolución del poder central de las Provincias Unidas en el año anterior, en una entidad con autonomía y personalidad política. Durante las décadas de 1820 y 1830 consolidó su estructura institucional y experimentó un importante proceso de expansión territorial y crecimiento económico. En este marco, incorporó a gran parte de la provincia de Misiones que había sido organizada sobre los territorios ocupados por las antiguas reducciones jesuíticas. Esto le posibilitó, además, agregar a su territorio un amplio litoral sobre el río Uruguay.

Es importante recordar aquí que una característica peculiar del territorio de la provincia de Corrientes radica en la multiplicidad de ríos y esteros que surcan su territorio. En este contexto, el complejo determinado por los esteros del Iberá y el río Corrientes cobra particular importancia ya que determinó una división natural del territorio muy difícil de superar, sobre todo en épocas de creciente, con la tecnología e infraestructura disponible en la época. Esto comprometió la capacidad de la capital para ejercer su jurisdicción en toda la región sudeste correntina. Desde aquí el poder de la ciudad fue jaqueado en forma intensa y permanente. A partir de la década de 1840, la provincia de Corrientes fue cabeza de algunas de las revueltas más intensas contra el gobernador de la provincia de Buenos Aires, Juan Manuel de Rosas, lo que provocó que perdiese la estabilidad política y financiera que la había caracterizado durante las dos décadas anteriores. Esa circunstancia, a su vez, acentuó los procesos de militarización y de autonomización de las regiones de frontera provincial, en particular las situadas en el sur y en el litoral del río Uruguay.

En realidad, nuestro propósito aquí no reside en reseñar la evolución histórica de las organizaciones estatales mencionadas sino, simplemente, en plantear algunos problemas relativos a diversos aspectos de su trayectoria y que remiten, de manera más o menos directa, a temas como el ejercicio de la ciudadanía, el sufragio, la participación política, la organización territorial interna, la percepción de tributos y la estructura miliciana. Para todas estas cuestiones las Constituciones previeron algún tipo de respuesta. Una vez más, es preciso reiterar en este contexto que en el ámbito rioplatense existieron diversos intentos de fundar distintos tipos de organizaciones estatales y políticas muy amplias sobre la base de Cartas constitucionales. Éstas constituyeron fuentes y modelos de referencia para los ensayos los años que nos ocupan. Todas ellas eran, además, conocidas por quienes pensaban la organización política de los nuevos estados y provincias rioplatenses. Los intentos fallidos de 1819 y 1826, en el ámbito de 
las Provincias Unidas del Río de la Plata, fueron especialmente tenidos en cuenta en este contexto. En el caso de la Banda Oriental es preciso tener presente, asimismo, que en Montevideo se juró la Constitución gaditana, que el mismo Artigas había elaborado un proyecto de Constitución inspirado en la de Massachusetts de 1779 y que incluso rigieron allí las Constituciones portuguesa de 1820 y brasileña de $1824 .^{9}$

Las Cartas Constitucionales aquí examinadas adoptaron sistemas republicanos de gobierno y admitieron el principio de la división de poderes, aunque la del Paraguay concentró amplias facultades en el Poder Ejecutivo conformando un régimen que sería calificado por varios constitucionalistas de la época como autoritario y paternalista. ${ }^{10}$ Con matices establecieron sistemas de sufragio calificados y relativamente restrictivos e impusieron modelos de organización territorial interna unitarios y centralizados. Todas ellas se fundaron en el principio de la soberanía popular y procuraron reconstruir el poder gubernamental sobre la base de ideas modernas de la representación política.

Por otro lado, dichas Constituciones expresaron, en muchos casos, los proyectos de transformación de la sociedad que procuraban implementar las elites rioplatenses gobernantes. Sin embargo, la realidad de estas regiones se mostró, a menudo, difícilmente maleable a los proyectos de dichas elites. El análisis del contraste entre algunos de los postulados constitucionales, las realidades regionales y las prácticas políticas constituye, como ya hemos señalado, uno de los ejes de este trabajo.

\section{La conformación del orden político, la ciudadanía y el problema del sufragio}

Como en la mayor parte de Hispanoamérica, las elites o grupos de notables gobernantes se plantearon, a través de estas constituciones, entre otros desafíos, legitimar la construcción de un nuevo orden político fundado en la soberanía popular. Las Constituciones estatales definieron las

9 Al respecto puede verse Gross Espiell, Héctor: Las Constituciones del Uruguay, Ediciones de Cultura Hispánica, Madrid, 1956.

10 Juan Bautista Alberdi, el publicista argentino cuyos trabajos orientaron la redacción de la Constitución argentina de 1853, calificaba severamente al ordenamiento constitucional paraguayo de 1856 señalando que no podía encontrarse en el cuerpo del texto ninguna mención a la palabra "libertad". Véase al respecto el ya citado trabajo de Mariñas Otero, Luis: Las Constituciones..., pág. 27. 
condiciones del ejercicio de la soberanía y delimitaron claramente el uso del sufragio, principal mecanismo de legitimación de las autoridades públicas, aunque en muchos casos hubo leyes complementarias que reglamentaron ese mismo ejercicio. Las Cartas Magnas correntinas de 1821 y 1824 definieron el sufragio en un sentido muy amplio en el llamado nivel activo, es decir en el referido a aquellos que podían sufragar o elegir. Según estos textos constitucionales eran todos los nativos de la provincia mayores de veinticinco años y todos los extranjeros, siempre que hubiesen afincado en el país al menos un patrimonio por valor de cuatro mil pesos o ejerciesen algún arte o profesión útil y supiesen leer y escribir. Más restrictivos eran estos mismos textos constitucionales al determinar quienes podían recibir los sufragios y ser electos, es decir en el nivel pasivo. Para esto era preciso ser "residente" en el departamento donde se elegía y además "propietario". La Constitución de 1856 fue más restrictiva ya que estableció una serie de condiciones inhibitorias para el ejercicio del sufragio. Excluyó a deudores insolventes, a analfabetos y a los condenados por la justicia.

La Constitución uruguaya de 1830 también creó un gobierno representativo, pero lo fijó, desde un principio, en manos de una clase electoral mucho más reducida. Algunos historiadores han interpretado este hecho como una reacción contra el igualitarismo que había caracterizado el experimento artiguista signado por su radicalismo en materia agraria. Esta Carta Magna prohibía el voto del peón jornalero, del sirviente a sueldo y del soldado de línea, con el propósito de asegurar la autonomía del sufragante. Exigía, por otro lado, para ser electo diputado o senador, es decir para el voto pasivo, un capital mínimo o, en su defecto, profesión u arte que produjese una renta equivalente a dicho capital.

Similares exigencias definían a la ciudadanía en el Paraguay. Aquí el sufragio experimentó una evolución que, sólo parcialmente, fue condensada en los textos constitucionales. Como ya señalamos, el Congreso General de 1813 estaba compuesto por unos mil diputados electos en comicios libres por todos los "naturales" independientemente de su estado, clase o condición. Sin embargo, progresivamente, el sufragio fue restringido, como puede advertirse en las convocatorias posteriores. En 1842, ese sufragio pasivo fue limitado a los propietarios de tierras y la Reforma Constitucional de 1856 redujo el número de diputados del Congreso de doscientos a cien y decretó la abolición del sufragio universal masculino estableciendo que también los electores debían ser propietarios de tierras. 
En gran medida, la evolución de la cuestión del sufragio en estas Cartas constitucionales y en las leyes correspondientes refleja el agotamiento de los modelos igualitarios y jacobinos que pueden encontrarse en las primeras etapas de la revolución en Hispanoamérica. Ya a finales de la década de 1810, en muchos lugares de América del Sur, estas posturas fueron reemplazadas por otras más conservadoras que buscaban, de alguna forma, limitar los márgenes de la participación política. ${ }^{11}$

¿Cómo era la realidad del ejercicio del sufragio en estas regiones? Tal vez pueda extraerse una forma de entender aspectos sustanciales relativos a la participación y a la construcción del poder político de algunas de las reflexiones vertidas por el gobernador de la provincia de Corrientes en la década de 1850, Juan Pujol. Éste era un típico letrado de los tiempos postindependentistas, formado en la Universidad de Córdoba, al igual que Gaspar Rodríguez de Francia, y cuyo capital principal eran sus conocimientos y habilidades políticas. Pujol elaboró un proyecto para reformar institucionalmente la Provincia de Corrientes fundado en la idea, común a muchos ilustrados rioplatenses, de que era posible, desde el ejercicio del poder gubernamental, modelar la realidad institucional, política y social de la provincia. El ámbito en el que estos proyectos iban a desarrollarse sería el municipal o departamental. Éste era, en definitiva, el espacio para la creación de una nueva ciudadanía política, signada por la presencia de inmigrantes y pequeños propietarios y el ámbito natural en el que debía asegurarse la extensión y el ejercicio de las libertades civiles y políticas.

Pujol concebía al sufragante en términos estrictamente individuales, como hombres independientes y autónomos para emitir su opinión. Lo entendía libre de toda coacción derivada ya fuese de lazos patronales o de organizaciones milicianas. Advertía claramente, sin embargo, que, en cambio, la realidad electoral estaba protagonizada y monopolizada, como en otros puntos del espacio sudamericano, por actores colectivos fuertemente militarizados, lo que inhibía, desde su perspectiva, la participación electoral del conjunto de los ciudadanos. En octubre de 1853, por ejemplo, en una de las primeras elecciones realizadas en la provincia bajo su gobierno, Pujol manifestaba a los presidentes de la Mesa electoral su preocupación

11 Sobre la evolución del voto en la Hispanoamérica del siglo XIX pueden verse los trabajos compilados por Sábato, Hilda: Ciudadanía política y formación de las naciones, FCE, México, 1999 y Annino, Antonio: Historia de las elecciones en Iberoamérica, FCE, Buenos Aires, 1995. 
por la legitimidad de las nuevas autoridades ya que, sobre dieciocho mil almas habilitadas para votar, sólo lo habían hecho ciento veintitrés personas. Para él, la ausencia de votantes y la falta de participación generaba un problema de legitimidad política que, a la vez, dejaba peligrosamente abierto el espacio para que el conflicto interno de las elites se resolviera únicamente a través de las armas.

¿Quiénes eran los que en Corrientes organizaban y canalizaban la movilización política y controlaban los actos electorales, que, como ya señalamos, eran los principales mecanismos de legitimación de la autoridad pública? Los políticos y letrados a cargo del gobierno destacaban cómo, a menudo, cuando la Guardia Nacional se movilizaba, los "paisanos" no iban a votar. El peso de las milicias departamentales, al mando del comandante de cada localidad, cumplía aquí un papel central ya que eran quienes canalizaban en la mayor parte de la provincia la movilización de los habitantes del departamento. La expresión del voto siguió siendo aquí, hasta finales del siglo XIX, un fenómeno esencialmente colectivo y ligado directamente a la organización miliciana. En los últimos años, muchos de los estudiosos de la política latinoamericana del siglo XIX han visto en estas formas de integración en la milicia uno de los mecanismos centrales de canalización de la participación política. Los testimonios del caso correntino nos presentan una imagen más matizada del problema. Para muchos de los protagonistas del proceso político provincial, la hegemonía miliciana era, justamente, el principal factor que impedía el ejercicio pleno de los derechos políticos por parte de los "vesinos". Así lo revela, por ejemplo, un debate en la legislatura correntina en una fecha tan tardía como junio de 1866. Una discusión sobre la validez del acto electoral en un departamento cercano a la capital mostraba un claro problema de legitimidad también vinculado al escaso número de votantes. Se denunciaba allí la coacción abierta de los jefes milicianos a los sufragantes, lo que había provocado la abstención del vecindario. Estos testimonios permiten advertir, además, cómo la expresión del voto, todavía en esos tiempos, constituía un fenómeno esencialmente colectivo y manifestaba con claridad el fracaso de los proyectos diseñados durante la década anterior, que veían en el sufragante a un individuo autónomo y desvinculado de lazos de dependencia.

Los mecanismos de movilización política en la Banda Oriental no eran, en este sentido, muy distintos. Diferentes caudillos, asentados en las zonas rurales, organizaban la movilización electoral. Como en el caso 
correntino, aquí también se evidenciaban las dificultades de la ciudad para ejercer el control sobre la campaña. Una larga confrontación, conocida justamente como la Guerra Grande, se inició en 1839 y culminó en 1852. El conflicto uruguayo se articuló fuertemente con los problemas políticos rioplatenses y brasileños en términos generales. $\mathrm{Al}$ respecto, los bajos índices de participación electoral se verificaban también en la Banda Oriental. Según Carlos Real de Azúa, en elecciones realizadas en 1842, sólo ejercía el sufragio en la capital, Montevideo, menos del 7\% de la población y la proporción era mucho más baja en el resto del país. De acuerdo con el mismo autor, esta democracia "censitaria" llevó a que la "masa popular" adoptase otras formas de expresión política diferentes a las electorales. ${ }^{12}$ Esta circunstancia explica, en gran medida, el estado permanente de guerras civiles que recorre la historia uruguaya hasta 1870.

\section{La organización interna de los Estados}

El ejercicio de los derechos políticos y del sufragio estaba estrechamente vinculado con los aspectos relativos a la organización interna del Estado. Es preciso señalar que muchos de estos territorios estaban prácticamente "vacíos" y que las comunidades indígenas que los habitaban fueron expulsadas o experimentaron un rápido proceso de declinación demográfica. Las ciudades que organizarían y estructurarían estos territorios ejercían durante la etapa colonial una jurisdicción territorial muy restringida y se encontraban subordinadas a Buenos Aires. Tras la disolución del poder central fueron afirmando y definiendo su jurisdicción a la vez que extendieron el espacio sobre el que ejercían ese mismo dominio. El problema de la territorialidad constituía, en verdad, un tema de construcción y de verdadera "ingeniería institucional" que se resolvió a partir de la creación y organización de las estructuras departamentales. Estas últimas estaban controladas, al menos desde el punto de vista constitucional, por el Poder Ejecutivo asentado en la ciudad capital. Las estructuras departamentales han sido escasamente estudiadas, a pesar de que sobre ellas se canalizaban y organizaban los actos electorales, las milicias e incluso gran parte del sistema de percepción de impuestos.

12 Véase Real de Azúa, Carlos: El Patriciado Uruguayo, Ediciones Asir, Montevideo, 1961, pág. 95 
Tanto Corrientes, como Uruguay y Paraguay establecieron una organización institucional interna unitaria sobre la base de la división departamental. Al frente de cada uno de esos departamentos había un funcionario que recibía la denominación de jefe político en Uruguay o comandante departamental en Corrientes ${ }^{13}$ siendo designado en todos esos Estados por el Poder Ejecutivo. En algunos casos, como en la Banda Oriental, estos jefes eran asesorados por Juntas Municipales cuyos miembros debían reunir requisitos en términos patrimoniales que, a menudo, eran más exigentes que los que se pedían a diputados o senadores. Los jefes tenían atribuciones amplias que podían abarcar, además de las ya mencionadas, la administración de justicia de carácter local o la instrumentación de las obras públicas. Una de las claves del desarrollo de estos Estados remite, a nuestro entender, también aquí, a la capacidad del Poder Ejecutivo, asentado en la ciudad capital, y de las elites gobernantes para llevar a cabo las designaciones de los comandantes y controlar la vida política en los departamentos.

Desde el punto de vista constitucional, puede advertirse así cómo la centralización política y administrativa prevista por la Constitución uruguaya era sumamente rigurosa. Las Juntas económicas administrativas incluidas en el documento de 1830 e integradas por vecinos del Departamento que asesoraban al jefe político tenían un margen de acción muy restringido. Prácticamente se desconocía aquí el poder municipal autónomo. Un abogado y constitucionalista colombiano, Justo Arosemena, que examinó las constituciones sudamericanas en 1870, señalaba, comentando precisamente la Constitución uruguaya, que la opresión que se ejercía sobre los distritos locales constituía un viejo resabio del sistema colonial español. ${ }^{14}$

Es preciso, de todos modos, tener en cuenta que la capacidad para modelar y actuar sobre el territorio era diferente en las distintas regiones de Hispanoamérica. En el Río de la Plata, el carácter de territorio de frontera,

13 A partir de 1860, en Corrientes, los comandantes departamentales fueron reemplazados por jefes políticos con el propósito de limitar el ejercicio de atribuciones militares por parte de estas autoridades. Véase al respecto Schaller, Enrique: "La Jefatura Política en la Provincia de Corrientes" en XVIII Encuentro de Geohistoria Regional, Resistencia, 1999 (edición electrónica).

14 Arosemena, Justo: "Las Constituciones políticas... pág. 321; se señalaba aquí en referencia a la falta de autonomía municipal: "Esa tutela á que el distrito se halla todavía sujeta en casi toda la América del Sur, es un resabio de la legislación i de las costumbres españolas, para quienes la vida propia de los pueblos i aldeas es una herejía política, como lo fuera entre los romanos la vida civil de los hijos i de las esposas". 
en muchos casos caracterizado por una extremadamente baja densidad de población y por la ausencia de corporaciones o estamentos en condiciones de esgrimir derechos de jurisdicción sobre la misma región, permitía la puesta en marcha de verdaderos procesos de "ingeniería territorial" con, al menos en teoría y en principio, un severo control desde la ciudad que organizaba los intentos de colonización.

Sin embargo, como señalamos, aunque las constituciones fijaban regímenes fuertemente centralizados, la realidad política de cada uno de los Estados analizados presentaba panoramas distintos. Fue probablemente en el Paraguay donde el poder del gobierno asentado en la ciudad capital se ejerció con mayor eficacia hasta 1870. El Paraguay fue dividido en 1820 en veinte delegaciones territoriales y a la cabeza de cada una de ellas había un comandante militar. A la vez, estas delegaciones estaban subdivididas en partidos controlados por jueces que reunían amplias atribuciones legales administrativas y económicas. Allí pudo entonces constituirse un régimen fuertemente centralizado y supervisado desde la cúspide del gobierno asentado en Asunción. Dentro de esta reducida elite de funcionarios había, además, fuertes diferencias internas. Los asentados en regiones de frontera o enclaves comerciales recibían el nombre de subdelegados y eran, por lo general, hombres de estricta confianza del "dictador perpetuo" de la República. Estos funcionarios, además de ocuparse de la gestión del gobierno local, protegían el comercio, coordinaban la defensa militar e incluso desempeñaban funciones relacionadas con el cobro de impuestos y la organización miliciana. Tanto los comandantes como los jueces eran periódicamente desplazados y rotaban entre partidos y departamentos. Hasta 1870, claramente, las autoridades del Estado conservaron el poder suficiente para controlar la actividad de estos jefes que se encontraban insertos en una estructura militarizada. ${ }^{15}$

No sucedió lo mismo en la Banda Oriental del Uruguay ni en la provincia de Corrientes, sobre todo a partir de que ambos estados se involucraran activamente en las guerras civiles rioplatenses desde el ya mencionado año de 1839. En este sentido puede señalarse que el Uruguay se caracterizó, durante toda la primera mitad del siglo XIX, por la imposibilidad de la capital, Montevideo, para controlar el territorio sobre el que ejercía, al menos en teoría, su jurisdicción. Los departamentos rurales eran el sitio por

15 Véase al respecto, Williams, John Hoyt: The Rise and Fall of the Paraguayan Republic, 1800-1870, University of Texas Press, Austin, 1979, págs. 81 y siguientes. 
excelencia de organización de la movilización política y militar y manifestaron una capacidad notable para neutralizar en diversas oportunidades a la capital. Hasta 1870 el poder central se manifestó incapaz de hacer sentir decididamente su dominio sobre la zona rural, dependiendo entonces del favor de los jefes políticos rurales. En este caso, la debilidad del Poder Ejecutivo asentado en Montevideo fue atribuida también a la Constitución, que otorgaba poderes demasiado amplios a las cámaras legislativas. Fructuoso Rivera, uno de los principales líderes políticos del Uruguay del siglo XIX, llegó a publicar un manifiesto en el que proponía la reforma de la constitución señalando que en ésta, al igual que en otras sancionadas en Hispanoamérica, se había debilitado excesivamente al Poder Ejecutivo reduciendo de manera peligrosa su esfera de acción. ${ }^{16}$

En el caso de Corrientes, la ciudad estaba controlada por una pequeña elite de mercaderes y burócratas. Este grupo gobernante manifestó una capacidad notable para controlar el territorio hasta finales de la década de 1830. A partir de entonces las circunstancias se modificaron sustancialmente a raíz de la extensión de su territorio y la incorporación de nuevas regiones en el marco de un proceso de expansión capitalista. Por otro lado, la provincia se involucró activamente en las guerras civiles del período a finales de esa misma década. Todas estas circunstancias alteraron fuertemente las jerarquías de poder territorial en la provincia.

Es preciso recordar aquí que, al menos en teoría, el gobernador, como sucedía en el Uruguay y el Paraguay, tenía el derecho de designar al comandante departamental o jefe político. Los Departamentos se encontraban al mando de un jefe militar, designado desde la década de 1820 por el gobernador y considerado agente y auxiliar de éste. Hacia 1853 la provincia de Corrientes se encontraba ya dividida en 18 Departamentos que estaban bajo el control de un comandante militar. También aquí, teóricamente, cada uno de estos comandantes era auxiliado por unos pocos funcionarios, en particular por uno o varios jueces de paz, aunque en el sur de la provincia, sobre todo al principio del proceso colonizador, el primero acumulaba

16 Señalaba Rivera: "Ningún error, sin embargo, puede ser más pernicioso: el Poder Ejecutivo, encargado por la naturaleza de nuestros gobiernos de la Administración inmediata de los negocios públicos, de la seguridad interior y defensa exterior del estado, necesita una acción vigorosa y concentrada, singularmente en países donde el hábito de la desobediencia, ha llegado a confundirse con el espíritu de Libertad y donde la aptitud para la administración no es común...”, citado en Pivel Devoto, Juan F., y Ranieri de Pivel Devoto, Alicia: Historia de la República Oriental del Uruguay, Editor Raúl Artagaveytia, Montevideo, 1945, pág. 115. 
las funciones de los jueces. Estos últimos además operaban como autoridades en las distintas divisiones del Departamento; en otros puntos del espacio rioplatense actuaban como mediadores y árbitros en los conflictos suscitados en las zonas rurales. Era de particular relevancia en este contexto su intervención en las disputas vinculadas con derechos de posesión y propiedad de la tierra. De su actuación dependía entonces, a menudo, el mantenimiento de la paz y el orden en estas regiones.

Los jefes departamentales, por su parte, ejercían en Corrientes atribuciones muy amplias que incluían desde el reclutamiento de tropas y las funciones policiales hasta las responsabilidades por la higiene y las obras públicas. En épocas de guerra tenían también facultades discrecionales para aplicar contribuciones forzosas. El jefe departamental aseguraba entonces el poder del estado en las áreas de frontera (actuaba en representación del gobernador) y oficiaba como intermediario entre la sociedad local y el poder asentado en la capital. En las áreas de frontera o de reciente colonización, además, podía manejarse con un alto grado de discrecionalidad a partir de la acumulación de cuotas considerables de poder en lo fiscal, judicial y militar. Como ya señalamos, también allí, los representantes de la autoridad pública actuaban sobre un vacío institucional y social, sobre un espacio en torno al cual no había elites o grupos de notables fuertemente arraigados ni instituciones con raíces antiguas como las vinculadas con las corporaciones eclesiásticas.

Además, estos jefes, en tanto máximas autoridades municipales, podían ejercer el control de las elecciones a partir de las cuales se designaba a los miembros de la legislatura local, ya que el Reglamento Provisorio Constitucional de 1824 había establecido que el juez y el comandante de cada Partido presidiesen y organizasen los actos electorales. ${ }^{17}$ Ya las autoridades nacidas de la revolución contra el dominio de la provincia de Entre Ríos de diciembre de 1821 habían dispuesto que los comandantes militares de los departamentos se ocupasen de la elección de los diputados por parte de los miembros del vecindario, encareciéndoles entonces que se ajustasen a la "libre y espontánea voluntad de los ciudadanos". ${ }^{18}$

17 Véase "Reglamento Provisorio Constitucional de la Provincia de Corrientes", septiembre 22 de 1824, Sección Tercera. En Recopilación de Constituciones de la Provincia de Corrientes, Edición Oficial, Imprenta del Estado, Corrientes, 1921. Un análisis de la estructura departamental y de las disposiciones que la orientaron puede leerse también en Gómez, Hernán: Instituciones de la Provincia de Corrientes, Imprenta del Estado, Corrientes, 1921.

18 Gómez, Hernán: Provincialización de Corrientes, Imprenta del Estado, Corrientes, 1915. 
Pero el gobierno provincial pudo ejercer plenamente sus atribuciones para nombrar y controlar a los jefes departamentales en las localidades más cercanas a la capital de la provincia. Una vez más debemos recordar que ese gobierno incorporó toda la región de las antiguas misiones jesuíticas situadas al sur del río Corrientes. Sobre toda esa zona hubo, en la década de 1830, un intenso proceso de ingeniería estatal ejercido desde la capital. Sin embargo, por razones de índole diversa, en particular geográficas y vinculadas con la imposibilidad de superar ciertos límites territoriales con la tecnología existente, el poder del gobierno provincial en aquella zona encontró fuertes limitaciones y éstas se acentuaron con el proceso de militarización de la región. La intensidad allí de las guerras civiles de la primera mitad del siglo XIX hizo que la provincia experimentase un fuerte proceso de descentralización interno y de alteración profunda de la jerarquía territorial. A mediano plazo esto se expresó en la consolidación de una estructura en la que se articularon fuertemente el poder político local, la representación de la autoridad pública, la jefatura miliciana y la propiedad de grandes extensiones de tierra.

Es preciso tener en cuenta tanto en el caso correntino como en el de la Banda Oriental que, a menudo, la misma dinámica de la sociedad de frontera provocaba la aparición de nuevas elites que, en algunos casos, ascendían como agentes del gobierno central pero, por diferentes razones, derivadas de la misma dinámica económica de la región, de su aislamiento, en algunos casos, y en otros de su posición estratégica en relación a los procesos de militarización, adquirían márgenes notables de autonomía. En la gran mayoría de los casos, estas circunstancias se tradujeron en un estado permanente de inestabilidad política.

\section{Constituciones, prácticas políticas y vicisitudes institucionales: algunas reflexiones sobre el caso correntino}

En esta perspectiva creemos particularmente útil realizar algunas observaciones sobre al caso correntino, que remiten a las consecuencias de la consolidación de esta estructura signada por la alteración de las jerarquías territoriales internas ya en el marco de integración de la provincia en el Estado nacional. Como señalamos anteriormente, las autoridades del gobierno provincial asentado en la capital correntina no lograron ejercer su dominio sobre las regiones de frontera del sur de la provincia. Allí se 
verificó un proceso en el que coincidieron, a mediano y largo plazo, el poder miliciano, la representación de la autoridad pública y la posesión de inmensas extensiones de tierra. Esto hizo, como ya hemos visto, que estas regiones conservaran cuotas relevantes de autonomía. A la vez, esto se tradujo en inestabilidad política, rebeliones permanentes resueltas a menudo, durante la segunda mitad del siglo XIX, a través de la intervención federal.

Por otro lado, esta estructura departamental, impregnada de las características que acabamos de señalar, impidió que la provincia pudiese construir un sistema viable de recursos propios. Su principal fuente de recursos hasta 1853 provenía del impuesto aduanero pero con la sanción de la Constitución nacional se abolieron las aduanas interiores. El impuesto aduanero pasó a ser patrimonio del Estado nacional y este último construyó así su base fiscal sobre los recursos generados por las aduanas. Los estados provinciales debían obtener los fondos para su funcionamiento interno a partir de impuestos sobre la producción o la tierra y, al menos en teoría, el principal de ellos era la contribución directa, fijada en un cuatro por mil de los capitales en giro. La formación del catastro, la valuación de los bienes, la percepción de los impuestos quedó a partir de entonces en manos de comisiones departamentales, fortalecidas a raíz de la alteración de las jerarquías territoriales antes mencionadas. Esto tuvo consecuencias negativas para el sistema fiscal de la provincia a mediano plazo, ya que ese sistema se reveló escasamente eficiente a la hora de lograr el cobro de los impuestos. Como lo expresaba el mismo gobernador Pujol en 1858, la contribución directa “....que por sí solo debía costear gran parte de los gastos de la administración..." no producía más que la cuarta parte del monto asignado en el cálculo de recursos. Dicho mal tenía su origen, para el gobernador, en la deficiencia de la ley que dejaba "....al arbitrio de los capitalistas, la avaluación de los capitales...”. Esto implicaba, sostenía Pujol, imponer una contribución voluntaria, “... es decir que el contribuyente dé lo que quiera, no lo que debe dar en proporción a la masa de bienes que posea....." ${ }^{19}$

Esta circunstancia tuvo, a la vez, consecuencias fuertemente negativas para el futuro provincial, puesto que el estado debió buscar mecanismos para sortear sus crecientes déficits y uno de ellos fue la venta de la tierra

19 Juan Pujol, en Corrientes en la Organización Nacional, Editorial Kraft, Buenos Aires, 1911, tomo IX, págs. 21-34. 
pública. El estado se desprendió en forma rápida y desordenada a lo largo de gran parte de la segunda mitad del siglo XIX de su patrimonio territorial, lo que dio lugar a un proceso acelerado de concentración de la propiedad. Esto impidió, a mediano plazo, la constitución de una red de pequeños propietarios autónomos con capacidad política para intervenir de forma independiente y autónoma en los actos electorales, tal como lo había imaginado el mismo Pujol.

Otro mecanismo utilizado para sortear el problema del déficit redundó en la estrecha dependencia del subsidio del Estado argentino. La Constitución nacional de 1853 contempló el otorgamiento de subsidios ordinarios de la Nación a los estados provinciales y Corrientes fue beneficiaria de este sistema. Éste fue uno de los factores que conspiró contra la autonomía del estado provincial y contra su capacidad para incidir en las decisiones nacionales. Varios intelectuales de la provincia cuestionaron, sobre esta base, a finales del siglo XIX la existencia misma de un sistema federal. No era posible, se sostenía, en este contexto, caracterizado por la imposibilidad de los estados provinciales de recaudar lo suficiente para afrontar sus gastos ordinarios, conformar un verdadero sistema federal. $\mathrm{La}$ dependencia del Estado nacional impedía, desde esta perspectiva, la concreción de un verdadero federalismo. ${ }^{20}$

\section{Reflexiones finales}

Durante el período de las guerras de independencia, las sociedades rioplatenses experimentaron un intenso proceso de movilización política que abrió cauces a la participación de sectores que habían ocupado hasta entonces un lugar marginal en términos regionales e incluso sociales. También en este contexto se vivieron algunas experiencias signadas por un tono fuertemente igualitario, como las acaecidas durante la hegemonía artiguista en la Banda Oriental. A partir de 1820, después de la fragmentación del antiguo Virreinato y el surgimiento de un conjunto de estados autónomos, fueron sancionadas una serie de Cartas constitucionales en un contexto signado por el predominio de las orientaciones conservadoras que siguió al proceso de radicalización y democratización que trajo la primera déca-

20 Al respecto véase Bas, Arturo: Derecho Federal Argentino, Valerio Abeledo Editor, Buenos Aires, 1927. 
da revolucionaria. Las elites políticas procuraban, a partir de estas Constituciones, controlar y canalizar los procesos de movilización política y esto se expresó, entre otros aspectos, a través de limitaciones al ejercicio del sufragio activo y pasivo con base en calificaciones vinculadas con la propiedad, el oficio, la edad y la residencia. Por otro lado, en términos generales, estas Cartas constitucionales adaptaron formas políticas centralistas que, en muchos casos, constreñían fuertemente y, en otros, directamente anulaban la autonomía municipal, aunque veían, en ocasiones, en este ámbito el espacio natural para el ejercicio de los derechos civiles y políticos.

Muchos de quienes participaron activamente en la elaboración de estos textos constitucionales ejercieron al mismo tiempo el Poder Ejecutivo y ocuparon puestos relevantes en la justicia o en las legislaturas de dichos estados. Participaban a menudo de la idea de que era posible una transformación sustancial de las estructuras económicas, sociales y políticas a partir del ejercicio del gobierno. De acuerdo con esta concepción, esas sociedades tenían que ser moldeadas, en la mayoría de los casos, según los ideales modernos: el sufragante, por ejemplo, debía ser un individuo autónomo, con capacidad para tomar decisiones en el marco de un municipio más actual. Como en muchos lugares de Hispanoamérica, también aquí, la realidad se mostró difícilmente maleable, mostrando la supervivencia y el predominio de actores colectivos y de una ciudadanía política más relacionada con el ejercicio conjunto de las armas que con el sufragio individual. La participación se canalizó por vías y a través de modalidades distintas a las postuladas por una parte de estas elites. Los ideales modernos, expresados a menudo en la letra de las Constituciones, se vieron así contrastados aquí con prácticas políticas que remitían a las tradiciones propias del Antiguo Régimen concebido como una sociedad integrada más bien por actores corporativos que individuales. En este, como en otros casos, podía advertirse una compleja articulación de ideas, prácticas y tradiciones de diferente origen. Como ha señalado Hilda Sábato, entre los derechos definidos por leyes y constituciones y las expectativas de los diferentes sectores de la sociedad se configuró un amplio terreno para el conflicto y la negociación. ${ }^{21}$

La organización y control del territorio fue uno de los problemas centrales que las elites políticas procuraron resolver a partir de los textos cons-

21 Sábato, Hilda: “Introducción”, en Sábato, Hilda: “Ciudadanía...”, págs. 11-29. 
titucionales. Es preciso tener en cuenta que el problema de la territorialidad asumía aquí características peculiares vinculadas al hecho de que gran parte de los espacios físicos sobre los que dichas elites procuraban ejercer su control estaban prácticamente deshabitados como consecuencia del exterminio y desaparición de extensas comunidades indígenas o del proceso de expulsión de poblaciones como resultado de las propias guerras de la independencia. Por otro lado, toda la región había vivido muy recientemente, con la creación del Virreinato del Río de la Plata en 1776, un proceso de reorganización del territorio que no había terminado de cristalizar. Todas estas circunstancias permitían un verdadero proceso de ingeniería territorial que posibilitaba, a la vez, planificar la organización administrativa de los territorios y su proceso de repoblación. Para esta administración se organizó, además, una estructura de gobierno generalmente unitaria al mando de comandantes departamentales o jefes políticos auxiliados, en muchas ocasiones, por jueces de paz.

Las Constituciones postulaban el dominio del territorio del estado desde las capitales. Sin embargo, la capacidad del centro urbano capitalino para controlar el territorio sobre el que ejercía teóricamente su jurisdicción fue cuestionada, con éxito en muchos casos. En el correntino, la ciudad experimentó, en el contexto de un proceso de extensión significativa del espacio de su jurisdicción, notorias dificultades para ejercer dicho dominio debido a impedimentos de carácter geográfico. En la Banda Oriental, el estado de guerra civil permanente que caracterizó su vida institucional y política revela también, en parte, el aislamiento de la ciudad y su incapacidad para controlar su territorio. El caso del Paraguay es probablemente el más exitoso. El control que Asunción ejerció, prácticamente sin trabas, sobre el conjunto del territorio terminaría más tarde, a consecuencia de los efectos de la guerra del Paraguay. ${ }^{22}$

En este contexto, cabe también formular la pregunta en torno a la vigencia de ciertos principios básicos del orden constitucional liberal sancionado en estas Constituciones como el de la división de poderes. Desde esa perspectiva, la cuestión del funcionamiento del régimen republicano en estas regiones constituye un tema que indagar. Parece evidente, en muchos casos, que los habitantes de todo este espacio defendían, por ejemplo, su

22 Balances recientes de la guerra de la Triple Alianza pueden leerse en Whigham, Thomas: The Paraguayan War, University of Nebraska Press, Lincoln and London, 2002 y en Doratioto, Francisco: Maldita Guerra, Emecé, Buenos Aires, 2004. 
acceso a la tierra, apelando a derechos de raigambre muy antigua y tenían éxito en sus reclamaciones ante distintas instancias judiciales, sobre todo a principios del siglo XIX. Pero también, muchos de los episodios y conflictos desatados aquí revelan la incapacidad de los sistemas institucionales para hacer efectivas las garantías republicanas consagradas en los textos constitucionales. Esta falta de vigencia de dichas garantías, particularmente de las vinculadas con la existencia de una justicia independiente, se prolongaría en muchos estados provinciales de la Argentina hasta entrado el siglo XX. Uno de los politólogos más destacados de la época del centenario, Rodolfo Rivarola, denunciaba, todavía en 1908, cómo en muchos de esos estados se hacía notar la intromisión sistemática, pública y abusiva del Poder Ejecutivo en el Poder Judicial. ${ }^{23}$

Finalmente, una variable clave para explicar muchas de las vicisitudes de estos proyectos constitucionales remite al carácter de zona de frontera de los estados aquí analizados, los cuales asumieron como una de sus tareas centrales durante todo el siglo XIX el control de amplios territorios. En el conflictivo contexto de aquellos años estos territorios debían ser fuertemente militarizados lo que implicó, a menudo, la conformación de focos de poder que alcanzaron una autonomía relevante y significativa. La construcción del orden político fue entonces, por esta razón, resultado siempre de un proceso de negociación permanente entre distintos actores. Por un lado, las elites políticas y letradas asentadas en las distintas ciudades capitales y, por otro, los actores sociales ubicados en las regiones de frontera, dueños del poder militar y con capacidad para movilizar a los sectores subalternos. Estas circunstancias generaron un estado de inestabilidad permanente, hasta la consolidación de los estados nacionales avanzada la segunda mitad del siglo XIX y con la integración en el sistema capitalista internacional pudo ingresarse en una etapa de mayor estabilidad. La posibilidad de contar con recursos económicos y financieros adicionales permitió, en gran medida, que los estados lograsen ejercer, finalmente, el "monopolio de la violencia legítima" y eliminar las distintas expresiones del caudillismo mediante la consolidación, entre otras instituciones, de los ejércitos nacionales. De todos modos, también debe señalarse que, en muchos casos, estos actores fuertemente militarizados fueron integrados en las nuevas constelaciones de poder surgidas con los Estados nacionales. La consolidación de éstos implicó a menudo la represión de las disidencias

23 Rivarola, Rodolfo: Del Régimen Federativo al Unitario, Peuser, Buenos Aires, 1908. 
locales, pero también la integración y negociación con algunos de estos actores. El espíritu y la índole de las Constituciones no se modificó sustancialmente a partir de entonces pero sí lo hizo, a menudo, la relación de éstas con las realidades estatales y políticas. Pero el análisis de dicha relación a partir de finales del siglo XIX y principios del XX requiere de la presentación de otro tipo de preguntas y la formulación de nuevos problemas.

Recibido el 19 de julio de 2007 Aceptado el 10 de enero de 2008 